\title{
Effect of Cigarette Packaging Sealing on Cigarette Moisture Content
}

\author{
Jianbo Zhan ${ }^{1}$, Han Zheng ${ }^{1}$, Hao Wang ${ }^{1 *}$, Jun Jiao ${ }^{2}$, Ying Zhang ${ }^{1}$, Jiao Xie ${ }^{1}$, Zhenhua $\mathrm{Yu}^{1}$, Xiangzhen $\mathrm{Li}^{1}$, Xu Wang ${ }^{1}$, and \\ Xu Zeng ${ }^{1}$ \\ ${ }^{1}$ R\&D Centre, China Tobacco Yunnan Industrial Co., Ltd. 650231 Kunming, Yunnan, P.R.China \\ ${ }^{2}$ Kunming Cigarette Factory, Hongyunhonghe Tobacco (Group) Co.Ltd., Kunming, Yunnan, P.R.China
}

\begin{abstract}
The moisture content of cigarette tobacco directly affects the smoking quality and storage period of cigarettes. The influence of the sealing property of cigarette packets on the moisture of the cigarette was studied, and a solution to improve the sealing property of the small package was provided. At the same time, the standard boundary for judging the packaging tightness of cigarette packets is calculated. Under different temperature and humidity environment, the air flow rate of the same packing box is higher than that of the $30-40 \mathrm{~mL} / \mathrm{min}$ interval. Improvement measures were applied to determine the packing seal value index of soft package cigarettes under certain conditions
\end{abstract}

\section{Introduction}

The sealing of cigarette packaging is directly related to the moisture content and volatile aroma components of cigarettes. The moisture content of cigarettes directly leads to mildew and variation of smoking taste, which seriously reduces the storage time of cigarettes and reduces the sensory quality of cigarettes [1]. There are many reasons for the poor sealing of cigarette packing. During the production process of BOPP film packaging machine, thin film folds, relaxation, blanching, uncompacted surface and improper use of BOPP film will occur during the process of film folding or in the process of film folding or conveying to the iron. By improving the folding parts of the GDX2 small box transparent paper packaging, the entrance channel, the packing and folding tower and the side seal iron position can effectively solve the phenomenon of small box transparent paper relaxation, the wrong drawing of the wire and the side wrinkles, improving the product appearance quality [1]. The molding rotary tower, which is fixed by the FOCKE401 transparent paper packing machine, is replaced by a molding rotary tower with a box mold size adjustable, improving the quality of the forming heat seal on the side of the packing machine[2]. By improving the GDX2 model, the size of the curved tile and iron on the second station, the ironing device is added and the air in the lap of the BOPP film is removed, thus improving the packaging quality[3]. By eliminating the design defect of the sealing iron of the packaging unit, the packaging problem of ironing and wrinkling can be solved[4]. The effects of BOPP film's sliding performance, antistatic performance, stiffness, thermal sealing performance and optical properties were also analyzed. The influence of BOPP film characteristics on packaging quality was analyzed [5]. The research aimed at improving the external quality and influencing factors of the small box transparent packaging, and some scholars also put forward an effective improvement method [6-7]. There is no unified standard for the determination of the small box seal degree of cigarette at present, but the industry standard of 2013 YC/T1401998 "determination of the sealing degree of cigarette small box - inflating method" is applicable to the sealing test of soft cigarettes. [8-10]. Therefore, this paper covers the inspection of the sealing property of the soft package box.

A box of cigarettes, which intends to go into the consumers' hands, needs to go through the flow of industrial inventory to commercial inventory, and then to the retail counter, the process will go through 3 months to half a year or even longer. As an example of the retail counter period, the temperature variation range can reach $-15^{\circ} \mathrm{C} \sim 40^{\circ} \mathrm{C}$, the range of humidity varies from $15 \%$ to $95 \%$, and the importance of cigarette small box sealing to cigarette quality is known. The purpose of this paper is to find out the moisture change of the small package cigarette with different packing and sealing under the conditions of different temperature and humidity, and to find out the packing seal degree where the soft cigarettes should reach under certain conditions and to put forward the improvement measures.

\section{Experimental materials and methods}

\subsection{Experimental apparatus and samples}

Cigarette small box packing seal tester (model: YMOPT-1 manufacturer: YM International), microwave

\footnotetext{
* Corresponding author: neuwanghao@gmail.com
} 
moisture meter test instrument (model: TEWS manufacturer: Hamburg), constant temperature and constant humidity box (model: KBF720 manufacturer: Binder); test soft packet cigarette sample (Hongyun Honghe Group).

\subsection{Experimental principles}

The test soft cigarette samples were sealed, and then placed in three temperature and humidity conditions $\left(30^{\circ} \mathrm{C}, 30 \%\right.$ humidity, $30^{\circ} \mathrm{C}, 80 \%$ humidity). After 7 days of continuous placement, the moisture content of the cigarettes in different packing sealed boxes was detected and the changes between the initial moisture content were observed.

The compressed air is injected into the small box to make the pressure difference between the internal and external pressure of the small box. When determining the gas flow rate and the pressure in the package, for the measurement of the adiabatic state, according to the Bernoulli equation's theory on the outlet flow of the thin wall aperture, the small box seal degree can be determined by the following formula.

$$
\mathrm{A}=\frac{q}{60 \cdot c \cdot\left(\frac{p_{0}}{p_{1}}\right)^{\frac{1}{k}} \sqrt{\frac{2 k}{k-1} p_{1}^{\frac{k-1}{k}} p_{0} \frac{1}{k} V_{0}\left[1-\left(\frac{p_{0}}{p_{1}}\right)^{\frac{k-1}{k}}\right.}} \times 100 \%
$$

Where, $p_{l}=p+p_{0}$; $\mathrm{A}_{0}$ is the sealing degree, $\mathrm{mm}^{2} ; p_{1}$ is the air pressure on the package, $\mathrm{Pa} ; p$ is air pressure, $\mathrm{Pa}$; $p_{0}$ is the air pressure in the testing environment, $\mathrm{Pa}$, in the standard condition $\mathrm{P}_{0}=101325 \mathrm{~Pa} ; \mathrm{V}_{0}$ is the atmospheric air volume in test environment, $\mathrm{m}^{3} / \mathrm{kg}$, in the standard condition $\mathrm{V}_{0}=0.836 \mathrm{~m}^{3} / \mathrm{kg}, \quad \mathrm{C}$ is the coefficient, $\mathrm{C}=0.909$; $\mathrm{q}$ is the air flow rate, $\mathrm{mL} / \mathrm{min} ; k$ is the Adiabatic coefficient $(k=1.4)$.

\subsection{Testing method}

In the constant temperature and constant humidity room $\left(22 \pm 2^{\circ} \mathrm{C} 、 60 \pm 5 \%\right)$, the airtightness of the sample of 475 packages was detected, the cigarette package was opened and the BOPP film and the smoke bag were pierced. The sealing disc was absorbed by the BOPP film, and the air hole was separated from the outside, and the dry compressed air was injected into the small box for 7 seconds in a constant pressure $(1000 \mathrm{~Pa})$. The pressure difference between the inside and outside of the small box forms a differential pressure, recording the inflation flow displayed by the device. According to the inflatable flow through the cigarette small box, the samples were measured in accordance with $0-10 \mathrm{~mL} / \mathrm{min} ; 10-20 \mathrm{~mL}$ $/ \mathrm{min} ; 20-30 \mathrm{~mL} / \mathrm{min} ; 30-40 \mathrm{~mL} / \mathrm{min} ; 40-50 \mathrm{~mL} / \mathrm{min}$; $50-80 \mathrm{~mL} / \mathrm{min} ; 80-120 \mathrm{~mL} / \mathrm{min}$; more than $120 \mathrm{~mL} / \mathrm{min}$, divided into 8 groups. In each group one package was taken and the microwave moisture meter to measure the initial moisture was applied. 3 packages are taken in each group, and they are placed in the constant temperature and humidity box of 2 different conditions $\left(30^{\circ} \mathrm{C}, 30 \%\right.$ humidity, $30^{\circ} \mathrm{C}, 80 \%$ humidity).

\section{Results and discussion}

\subsection{Distribution of the sealing degree of cigarette smoke package}

The experimental data contains the test results of the sealing properties of 475 packages of cigarette packets, as shown in Fig. 1. A total of 475 packages of cigarette samples were tested, and 8 gradients were classified according to gas density. Among them, the average air sealing properties of the 475 packages is $42.5 \mathrm{~mL} / \mathrm{min}$, or more than $30 \mathrm{~mL} / \mathrm{min}$, accounting for $53 \%$.

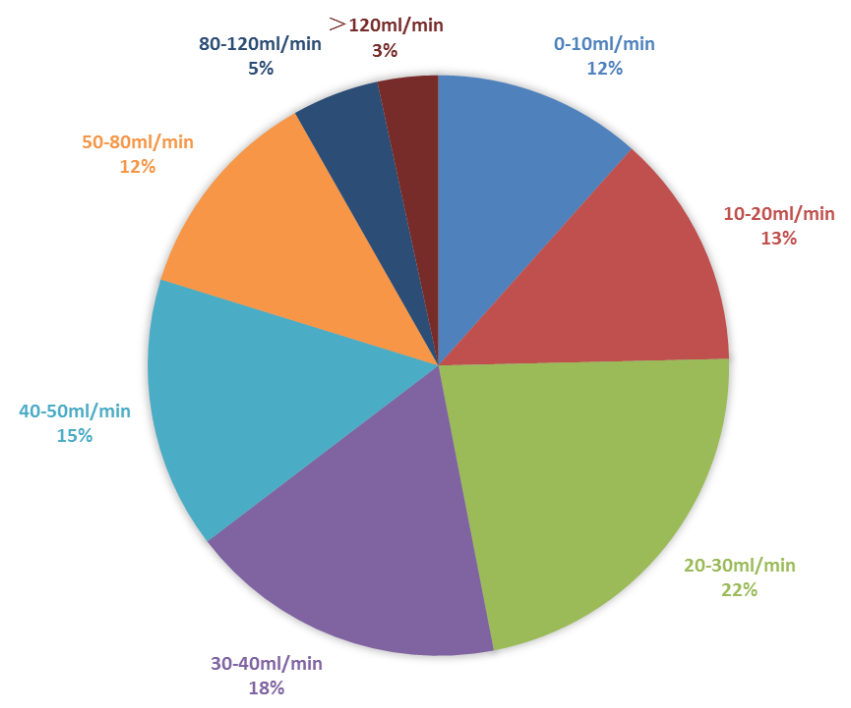

Fig.1 Duty chart of Sealing properties ranges

\subsection{Relationship between the sealing degree of cigarette pack and the moisture of cigarette}

In dry environment (temperature $30^{\circ} \mathrm{C}$, humidity $30 \%$ ) for 7 days, due to air sealing properties, the degree of moisture loss of cigarettes is also different. With the mean value of $11.7 \%$ initial moisture as reference, the moisture change is $11.51 \%$, the lowest value is $11.02 \%$, the mean value is $11.27 \%$, and the moisture of the cigarette is greatly reduced by 7 days at the temperature and temperature of $30^{\circ} \mathrm{C}$ and the humidity $30 \% .11 .7 \%$ of the water line that has exceeded the requirements of most enterprises.

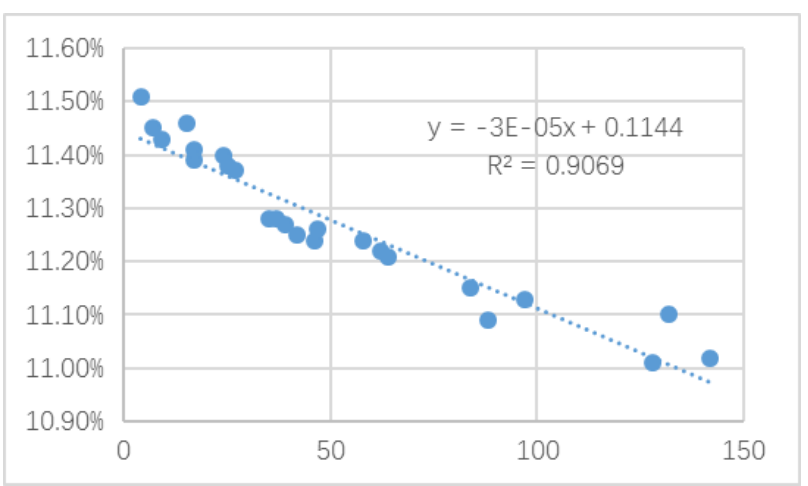

Fig.2 Regression trend of sealing degree and moisture variation of soft cigarette packages in dry environment 
According to the measured data, linear regression was carried out between the water content of the sample and the gas tightness value. The linear equation of water change for 15 days was stored for 15 days under the environment of temperature of $30 \%$ and the temperature of a single sample. With the change of the small box gas density, the moisture content of the sample changed according to the downward trend.

$$
y=-3 E-05 x+0.1144
$$

With the increase of the flow rate of the cigarette box, the moisture content of the cigarette box tends to decrease linearly.

It can be seen from Fig. 3 that in wet environment (temperature $30^{\circ} \mathrm{C}$, humidity $80 \%$ ) stored for 7 days, the degree of absorption of moisture in cigarettes is different because of the difference of air tightness. It is stored for 7 days at the temperature of $30^{\circ} \mathrm{C}$ and humidity $80 \%$, with the mean value of $11.7 \%$ initial moisture as reference. The moisture change is at the highest value of $12.69 \%$, the minimum value is $12.17 \%$, the mean value is $12.17 \%$. For $12.35 \%$, it increased by $0.65 \%$ compared with $11.7 \%$ of initial moisture. And with the increase of aeration flow, water showed an upward trend. The sample with an aerated flow greater than $40 \mathrm{~mL} / \mathrm{min}$, $50 \%$ has exceeded the moisture requirement of $12.5 \%$ of the enterprise requirements.

According to the measured data, linear regression was carried out between the water content of the sample and the gas tightness value. The linear equation of water change for 7 days was stored for 7 days under the environment of temperature of $80 \%$ and the temperature of a single sample. With the change of the small box gas density, the moisture content of the sample changed according to the downward trend.

$$
Y=4 E-05 x+0.1213
$$

With the increase of the flow rate of cigarette box, the moisture content increases linearly.

According to the above data, we can see that the cigarette small box within the same airtight range is placed in different environment for 7 days, and the moisture in the cigarette smoke shows a great difference, as shown in Fig. 3.

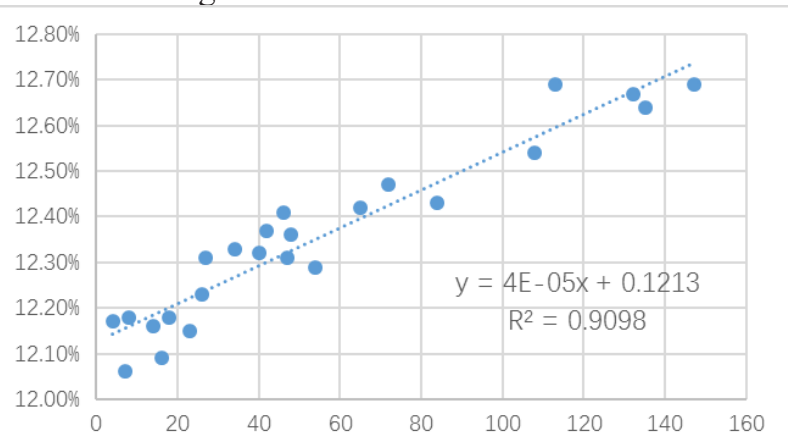

Fig.3 Regression trend of sealing degree and moisture variation of soft cigarette packages in humid environment

With the analysis of Fig. 1 (longitudinal coordinates as the mean of the moisture content of tobacco, the transverse coordinates are small box gas density values (inflated flow representation), we found that the degree of moisture absorption of tobacco branches increased with the increase of the gas density at the temperature of $30^{\circ} \mathrm{C}$ and the humidity of $80 \%$ in the environment (the gray line in the figure), and the corresponding curve showed an upward trend. When the temperature is $30^{\circ} \mathrm{C}$, and the humidity is $30 \%$ in the environment, and it is stored for 15 days, the moisture content of the tobacco branch increases with the increase of the gas density, and the corresponding curve shows a downward trend. Under the environment of $22^{\circ} \mathrm{C}$ and $60 \%$ humidity for 7 days, the moisture of small box cigarettes with the gas density below $30 \mathrm{~mL} / \mathrm{min}$ is basically consistent with the initial water line, and the small box moisture of the air tightness greater than that of $30 \mathrm{~mL} / \mathrm{min}$ decreases slightly, which is lower than the initial water mean line.

\subsection{Solutions}

For short-term quick solution, using the smoke package sealing tester to test the current packing line is appropriate to check the sealing property of the small packages, in order to further find out the influence of the soldering iron temperature and contact on the sealing property of the upper, lower and side parts of the small package. According to the improvement of the previous stage, the sealing standards of cigarette packets were formulated at the later stage, and the on-site QC plan should be formed.

\section{Conclusion}

There is a close correlation between the sealing property of cigarette packets and moisture content of cigarette. With the change of the sealing property of the cigarette box, the moisture content of the cigarette also changes correspondingly. That is, under the same environment, the moisture change rate increases with the increase of the air tightness of the cigarette case. Under different circumstances, the same packing air tight box, packing air tightness in the range of 20 to $30 \mathrm{~mL} / \mathrm{min}$ above, is obviously affected by temperature and humidity environment. According to this change trend, we can deduce the sealing index of cigarettes that should be achieved. It is found that the influence of iron temperature and sealing on the upper, lower and side sides of the package can be adjusted by on-site feedback and solved temporarily and quickly.

\section{Acknowledgment}

Financial supports from Science and Technology Project of China Tobacco Yunnan Industrial Co.,Ltd. (Grant Nos. 2017CP03 \& 2017CP01) are great acknowleged.

\section{References}

1. W.P. Zhao, Z. Xu. Pack. Eng., 21, 155 (2015)

2. P.L. Cai, B.G. He, J.F. Yang, et al. Pack. Eng., 5, 92 (2017)

3. K.T. Zhou. Toba. Sci. Tech., 12, 24 (2007) 
4. X.S. Zeng, B.G. He. Sci. Tech. Eng., 32, 8767 (2012)

5. Y. Feng. Pack. Eng., 1, 121 (2015)

6. Y.P. Bi, D.L. Sun. China Sci. Tech. Info., 5, 132 (2010)

7. W.F. Liu, W.P. Wang. Toba. Sci. Tech., 7, 48 (2004)

8. S.Q. Dong Toba. Sci. Tech., 2, 22 (2001)

9. G.Z. Chen. Plas. Pack. 3, 15 (2003)

10. X.W. Wang, C.R. Chi. Pack. Eng. 29, 56 (2008)

11. S.C. Xiong. Pro. Sym. Toba. Mach. 2 (2006)

12. P. Jiao, X.H. Bai, H.L. Li, et al. Pack. Eng., 31, 53 (2010)

13. H.G. Shan, Y.D. Ji. Heilongjiang Toba., 2, 19 (2001)

14. M. Long. Pack. Eng., 12, 27 (2007)

15. H.L. Li, P. Wen, Y.X. Dai, et al. Acta Taba. Sinica, 15, 10 (2009) 